\title{
Autologous Cytomegalovirus-specific Cytotoxic T-lymphocytes
}

National Cancer Institute

\section{Source}

National Cancer Institute. Autologous Cytomegalovirus-specific Cytotoxic T-

lymphocytes. NCI Thesaurus. Code C116732.

A population of autologous cytotoxic-T lymphocytes (CT Ls) specifically reactive to the herpes virus cytomegalovirus (CMV) with potential immunomodulating and antiviral activities. Upon administration with the autologous CMV-specific CT LS, these CT Ls lyse CMV-infected cells, thereby preventing or decreasing the occurrence of CMV viral disease, or reducing the amount of antiviral drug therapy needed to eradicate CMV. 